\title{
Respon Ketahanan Beberapa Varietas Cabai Rawit (Capsicum frutescens L.) Terhadap Pemberian NaCl secara In Vitro
}

In Vitro Resistance Respon of Varieties Cayenne pepper (Capsicum Frutescens L.) to give of $\mathrm{NaCl}$

Lita Adelia, Luthfi A. M. Siregar*, Khairunnisa Lubis

Program Studi Agroteknologi, Fakultas Pertanian Universitas Sumatera Utara, Medan 20155

*Coressponding author : e-mail: luthfi2004@yahoo.com

\begin{abstract}
This study was to determine the resistance of ten cayenne pepper (Capsicum frutescens L.) varieties to salinity stress in viro. This research used completely randomized design with two factors, they were cayenne pepper varieties with 10 varieties of Tetra Hijau, Pedas, Cakra Hijau, Sigantung, Wijaya, Sapade, Sret, Bara, Genie and Hanna 08 and $\mathrm{NaCl}$ concentration in growing media with five levels 0 ppm, 2500 ppm, 5000 ppm, 7500 ppm dan 10.000 ppm. The results showed that the variety of cayenne pepper and concentration of $\mathrm{NaCl}$ and interaction of both had significant effect on the crown fresh weight and root fresh weight. Sigantung varieties have the highest average on all observed characters.
\end{abstract}

Keywords: cayenne pepper, in-vitro, $\mathrm{NaCl}$, variety

\section{ABSTRAK}

Penelitian ini bertujuan untuk mengetahui ketahanan sepuluh varietas cabai rawit (Capsicum frutescens L.) terhadap cekaman salinitas $(\mathrm{NaCl})$ secara in vitro. Penelitian ini menggunakan Rancangan Acak Lengkap (RAL) dengan dua faktor. Varietas yang diuji adalah Tetra Hijau, Pedas, Cakra Hijau, Sigantung, Wijaya, Sapade, Sret, Bara, Genie dan Hanna 08 dengan konsentrasi garam $\mathrm{NaCl}$ pada media dengan 5 taraf yaitu 0 ppm, 2500 ppm, 5000 ppm, 7500 ppm dan 10.000 ppm. Hasil penelitian menunjukkan bahwa varietas cabai rawit, konsentrasi $\mathrm{NaCl}$ dan interaksi keduanya berpengaruh nyata pada bobot basah tajuk dan bobot basah akar. Varietas Sigantung memiliki data rataan tertinggi pada seluruh karakter amatan.

Kata kunci : cabai rawit, in-vitro, $\mathrm{NaCl}$, varietas

\section{PENDAHULUAN}

Cabai merupakan komoditas sayuran yang cukup strategis. Dari data yang diperoleh tahun 2013-2015 terlihat fluktuasi harga cabai rawit lebih tinggi dibandingkan cabai merah besar dan cabai merah keriting, pada bulan Desember 2014 harga rata-rata cabai merah besar mencapai Rp. 70,750/kg, cabai merah keriting Rp. 70,200/kg dan cabai rawit merah Rp. $85,150 / \mathrm{kg}$. Tingginya permintaan cabai pada waktu tertentu dan produksi cabai yang tetap mengakibatkan meningkatnya harga cabai (Nauly, 2016).

Salah satu kendala dalam peningkatan produksi pertanian adalah semakin luasnya lahan pertanian dialihfungsikan ke sektor lainnya (Sudana, 2005). Perluasan areal tanam baru umumnya ditujukan ke lahan-lahan kurang produktif akibat cekaman lingkungan. Diantara berbagai cekaman lingkungan kekeringan dan salinitas merupakan cekaman yang banyak dijumpai (Widiayani, 2016). Total luas lahan salin di Indonesia mencapai 440.000 ha yang terbagi menjadi lahan agak salin 304.000 ha dan lahan salin 140.000 ha (Sudana, 2005). Tanah tergolong salin apabila mengandung garam berlebih dalam tanah, besarnya kadar salin dalam tanah mengakibatkan ketidakseimbangan ion sehingga aktivitas metabolisme tumbuhan terganggu (Djukri, 2009). 
Cara alternatif yang efektif dan efisien untuk mengatasi cekaman pada tanaman yaitu dengan menggunakan varietas toleran. Untuk mengetahui tanaman yang toleran dapat dilakukan dengan meguji ketahanan beberapa varietas yang ada untuk dinilai tingkat ketahanannya berdasarkan konsentrasi cekaman yang digunakan (Suwignyo, 2007).

Seleksi cekaman secara in vitro dapat dilakukan dengan cara pemberian agens seleksi ke dalam medium tanam. Seleksi in vitro dinilai lebih efisien karena kondisi seleksi dapat dibuat homogen, tempat yang dibutuhkan relatif sedikit, dan efektivitas seleksi tinggi (Fauziah, 2016).

Bobot tanaman merupakan ukuran yang sering digunakan menggambarkan dan mempelajari pertumbuhan tanaman. Hal ini didasarkan taksiran bobot tanaman relatif mudah diukur dan merupakan integrasi dari hampir semua peristiwa yang dialami tanaman sebelumnya. Sehingga parameter ini dapat menjadi indikator pertumbuhan representatif untuk menggambarkan keseluruhan penampilan tanaman atau suatu organ tertentu (Sitompul dan Guritno, 1995).

Tingkat salinitas tanah dikelompokkan menjadi: (1) salinitas rendah dengan daya hantar listrik (DHL) $=2-4 \mathrm{mmhos} / \mathrm{cm} ;$ (2) salinitas sedang dengan daya hantar listrik $(\mathrm{DHL})=4-8 \mathrm{mmhos} / \mathrm{cm}$; (3) Salinitas tinggi dengan DHL sebesar 8-15 mmhos/cm; (4) Salinitas sangat tinggi dengan DHL lebih dari $15 \mathrm{mmhos} / \mathrm{cm}$ (Sunarto, 2001).

Berdasarkan Akbar (2010) diketahui nilai DHL media tanam dengan perlakuan beberapa konsentrasi $\mathrm{NaCl}$ sebagai berikut:

Tabel 1. Data pengukuran daya hantar listrik (DHL) media tanam

\begin{tabular}{cc}
\hline Konsentrasi NaCl & DHL $(\mathrm{dS} / \mathrm{m})$ \\
\hline $0 \mathrm{ppm}$ & 1,00 \\
$2.500 \mathrm{ppm}$ & 8,30 \\
$5.000 \mathrm{ppm}$ & 9,36 \\
$7.500 \mathrm{ppm}$ & 13,90 \\
$10.000 \mathrm{ppm}$ & 19,30 \\
\hline
\end{tabular}

Berdasarkan uraian di atas, penulis tertarik melakukan penelitian penyaringan varietas cabai rawit (Capsicum frutescens $\mathrm{L}$.) toleran terhadap kondisi cekaman salin secara in vitro dengan menggunkan agen seleksi $\mathrm{NaCl}$ pada media tanam, yang merupakan tahap awal dari kegiatan pemuliaan tanaman untuk menghasilkan varietas unggul cabai rawit yang tahan salin.

Tujuan penelitian ini adalah mendapatkan varietas tanaman cabai rawit $(C$. frutescens L.) yang toleran pada kondisi cekaman salinitas $(\mathrm{NaCl})$ secara in vitro.

\section{BAHAN DAN METODE}

Penelitian ini dilaksanakan di Laboratorium Kultur Jaringan Tanaman Program Studi Agroteknologi Fakultas Pertanian Universitas Sumatera Utara, Medan mulai bulan April 2017 sampai Agustus 2017.

Bahan yang digunakan dalam penelitian ini meliputi bahan eksplan: benih cabai rawit varietas Tetra Hijau, Pedas, Cakra Hijau, Sigantung, Wijaya, Sapade, Sret, Bara, Genie dan Hanna 08. Bahan penyusun media MS: larutan stok makronutrient; larutan stok mikronutrient, larutan stok vitamin, larutan stok iron, myoinositol, sukrosa dan agar. Bahan sterilisasi yaitu alkohol $70 \%$, aquadest steril, deterjen, dithane, benlate, chlorox, iodine, tween 20 dan spiritus. Bahan buffer $\mathrm{pH}: \mathrm{NaOH} 0,1 \mathrm{~N}$ dan $\mathrm{HCl} 0,1 \mathrm{~N}$. kertas label, kertas indikator $\mathrm{pH}$, aluminium foil. Alat yang digunakan dalam penelitian ini meliputi alatalat gelas, alat-alat diseksi, Laminar Air Flow Cabinet (LAFC), timbangan analitik, spatula, pipet tetes, alat sterilisasi (autoklaf, lampu spiritus, dan hans prayer penyemprot alkohol, oven), lemari pendingin, rak kultur, lampu flowrescenst, hot plate with magnetic stirrer, kamera.

Penelitian ini menggunakan Rancangan Acak Lengkap (RAL) dengan dua faktor. Faktor pertama adalah konsentrasi $\mathrm{NaCl}$ dengan 5 taraf, $\mathrm{G}_{0}=0 \mathrm{ppm} \mathrm{NaCl}, \mathrm{G}_{1}=$ $2.500 \mathrm{ppm} \mathrm{NaCl}, \mathrm{G}_{2}=5.000 \mathrm{ppm} \mathrm{NaCl}, \mathrm{G}_{3}=$ 7.500 ppm NaCl, G4 $=10.000$ ppm NaCl. Faktor kedua adalah varietas cabai rawit, terdiri 10 varietas, $\mathrm{V}_{1}$ : Tetra Hijau, $\mathrm{V}_{2}$ : Pedas, $V_{3}$ : Cakra Hijau, $V_{4}$ : Sigantung, $V_{5}$ : Wijaya, $V_{6}$ : Sapade, $V_{7}:$ Sret, $V_{8}:$ Bara, $V_{9}$ : 
Genie, $\mathrm{V}_{10}$ : Hanna 08. Masing-masing perlakuan diulang 3 kali.

Peubah amatan yang diamati adalah bobot basah tajuk dan bobot basah akar.

Data yang didapatkan dianalisis ANOVA dengan alat bantu Microsoft Exel, data hasil penelitian yang berpengaruh nyata maka dilanjutkan dengan DMRT (Duncan Multiple Range Test) pada taraf 5\%. Data dianalisis dengan menggunakan Microsoft Exel 2007.

\section{HASIL DAN PEMBAHASAN}

Berdasarkan hasil analisis statistik menunjukkan bahwa perlakuan varietas, konsentrasi $\mathrm{NaCl}$ dan interaksi keduanya berpengaruh nyata pada parameter bobot basah tajuk dan bobot basah akar.

\section{Bobot Basah Tajuk}

Rataan bobot basah tajuk dengan perlakuan beberapa varietas cabai rawit dan konsentrasi $\mathrm{NaCl}$ secara in vitro dapat dilihat pada Tabel 2.

Tabel 2. Bobot basah tajuk planlet dengan perlakuan beberapa varietas cabai rawit dan konsentrasi $\mathrm{NaCl}$ secara in vitro

\begin{tabular}{|c|c|c|c|c|c|c|}
\hline \multirow[b]{2}{*}{ Varietas } & \multicolumn{5}{|c|}{ Salinitas (ppm NaCl) } & \multirow[b]{2}{*}{ Rataan } \\
\hline & $\begin{array}{l}\mathrm{G}_{0} \\
(0)\end{array}$ & $\begin{array}{c}\mathrm{G}_{1} \\
(2.500)\end{array}$ & $\begin{array}{c}\mathrm{G}_{2} \\
(5.000) \\
\end{array}$ & $\begin{array}{c}\mathrm{G}_{3} \\
(7.500) \\
\end{array}$ & $\begin{array}{c}\mathrm{G}_{4} \\
(10.000)\end{array}$ & \\
\hline \multicolumn{7}{|c|}{ 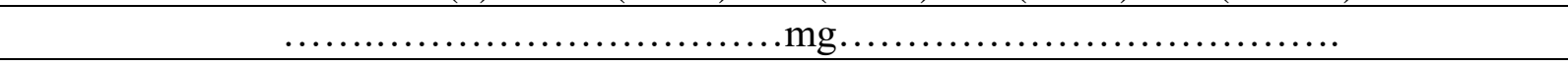 } \\
\hline $\mathrm{V}_{1}$ (Tetra Hijau) & $3.66 \mathrm{e}-\mathrm{h}$ & $3.93 \mathrm{e}-\mathrm{h}$ & $4.28 \mathrm{~d}-\mathrm{h}$ & $3.44_{\mathrm{e}-\mathrm{h}}$ & $0.99_{\mathrm{fg}}$ & 3.26 \\
\hline $\mathrm{V}_{2}$ (Pedas) & $4.14_{\mathrm{d}-\mathrm{h}}$ & $6.06 \mathrm{~d}-\mathrm{g}$ & $5.03 \mathrm{~d}-\mathrm{h}$ & $3.87 \mathrm{e}-\mathrm{h}$ & $3.82 \mathrm{e}-\mathrm{h}$ & 4.58 \\
\hline $\mathrm{V}_{3}($ Cakra Hijau $)$ & $1.82 \mathrm{f}-\mathrm{h}$ & $4.92 \mathrm{~d}-\mathrm{h}$ & $5.08 \mathrm{~d}-\mathrm{h}$ & $4.40_{\mathrm{d}-\mathrm{h}}$ & $3.56 \mathrm{e}-\mathrm{h}$ & 3.95 \\
\hline $\mathrm{V}_{4}$ (Sigantung) & $50.93 a$ & $36.21 \mathrm{ab}$ & $23.93 b c$ & $13.14_{\mathrm{cd}}$ & $10.65_{c-e}$ & 26.97 \\
\hline V5 (Wijaya) & $2.34_{\mathrm{f}-\mathrm{h}}$ & $3.68 \mathrm{e}-\mathrm{h}$ & $4.99_{\mathrm{d}-\mathrm{h}}$ & $2.15_{\mathrm{f}-\mathrm{h}}$ & $4.95 \mathrm{~d}-\mathrm{h}$ & 3.62 \\
\hline $\mathrm{V}_{6}$ (Sapade) & $3.82 \mathrm{e}-\mathrm{h}$ & $4.81_{\mathrm{d}-\mathrm{h}}$ & $7.55_{\mathrm{d}-\mathrm{g}}$ & $0.63_{\mathrm{fh}}$ & $4.21 \mathrm{e}-\mathrm{h}$ & 4.20 \\
\hline $\mathrm{V}_{7}($ Sret $)$ & $6.71_{\mathrm{d}-\mathrm{h}}$ & $2.67 \mathrm{e}-\mathrm{h}$ & $0.77_{\mathrm{fh}}$ & $0.43 \mathrm{~h}$ & $1.21_{\mathrm{fg}}$ & 2.36 \\
\hline $\mathrm{V}_{8}$ (Bara) & $5.83 \mathrm{~d}-\mathrm{h}$ & $7.13 \mathrm{~d}-\mathrm{f}$ & $0.87_{\mathrm{fh}}$ & $3.40 \mathrm{e}-\mathrm{h}$ & $1.52 \mathrm{f}-\mathrm{h}$ & 3.75 \\
\hline $\mathrm{V}_{9}$ (Genie) & $1.93 \mathrm{f}-\mathrm{h}$ & $4.31_{\mathrm{d}-\mathrm{h}}$ & $2.92_{\mathrm{e}-\mathrm{h}}$ & $4.02 \mathrm{~d}-\mathrm{h}$ & $4.44_{d-h}$ & 3.52 \\
\hline $\mathrm{V}_{10}($ Hanna 08) & $3.90 \mathrm{e}-\mathrm{h}$ & $4.54_{\mathrm{d}-\mathrm{h}}$ & $4.12 \mathrm{~d}-\mathrm{h}$ & $4.10_{\mathrm{d}-\mathrm{h}}$ & $1.31 \mathrm{f}-\mathrm{h}$ & 3.59 \\
\hline Rataan & 8.51 & 7.83 & 5.95 & 3.96 & 3.66 & 5.98 \\
\hline
\end{tabular}

Keterangan: Angka yang diikuti notasi huruf yang berbeda pada kolom dan baris yang sama adalah berbeda nyata berdasarkan Uji Jarak Berganda Duncan pada taraf 5\%.

Tabel 2 menunjukkan peningkatan konsentrasi garam meyebabkan bobot basah tajuk semakin rendah. Perlakuan $\mathrm{G}_{0} \mathrm{~V}_{4}(50.93$ mg) menghasilkan bobot basah tajuk lebih berat dibandingkan perlakuan lainnya. Sedangkan perlakuan $\mathrm{G}_{3} \mathrm{~V}_{7}$ menghasilkan bobot basah tajuk terendah $(0.43 \mathrm{mg})$. Pada $\mathrm{V}_{1}, \mathrm{~V}_{2}, \mathrm{~V}_{3}, \mathrm{~V}_{5}, \mathrm{~V}_{6}, \mathrm{~V}_{7} \mathrm{~V}_{8}, \mathrm{~V}_{9}$ dan $\mathrm{V}_{10}$ perlakuan $\mathrm{NaCl}$ mulai kontrol $\left(\mathrm{G}_{0}\right)$ sampai konsentrasi $10.000 \quad \mathrm{ppm} \quad\left(\mathrm{G}_{4}\right)$ tidak mempengaruhi bobot basah tajuk. Berbeda dengan $\mathrm{V}_{4}$ peningkatan konsentrasi $\mathrm{NaCl}$ mempengaruhi bobot basah tajuk, terutama pada kontrol $\left(\mathrm{G}_{0}\right)$ dan konsentrasi $2.500 \mathrm{ppm}$ $\left(\mathrm{G}_{1}\right)$ menunjukkan bobot basah tajuk yang lebih tinggi berbeda nyata dengan varietas lainnya.

Berdasarkan analisis ragam diketahui secara umum semakin tinggi konsentrasi $\mathrm{NaCl}$ maka pertumbuhan dan perkembangan tanaman semakin menurun. Pertumbuhan dan perkembangan cabai rawit terburuk pada perlakuan $\mathrm{NaCl} 10.000$ ppm hal ini diduga pada konsentrasi garam tersebut meracuni tanaman sehingga pertumbuhan tanaman terhambat, dijelaskan dalam Kasim (2010) kelarutan garam yang tinggi dalam lingkungan seleksi meningkatan tekanan osmotik pada media tanaman sehingga air yang diserap akar tanaman berkurang. Secara 
khusus kadar garam yang tinggi menyebabkan keracunan bagi tanaman dengan merusak selsel yang sedang tumbuh sehingga pertumbuhan sel tidak berlangsung dan membatasi suplai hasil-hasil metabolisme esensial bagi sel. Menurut Salisbury dan Ross (1995) masalah potensial lainnya bagi tanaman adalah mengurangi ketersedian $\mathrm{K}^{+}$ dan $\mathrm{Ca}^{++}$dalam media tanam dan menghambat transportasi dan mobilitas unsur hara tersebut ke daerah pertumbuhan sehingga mengurangi pertumbuhan organ vegetatif dan reproduktif tanaman.

\section{Bobot Basah Akar}

Rataan bobot basah akar dengan perlakuan beberapa varietas cabai rawit dan konsentrasi $\mathrm{NaCl}$ secara in vitro dapat dilihat pada Tabel 9.

Tabel 3. Bobot basah akar planlet dengan perlakuan beberapa varietas cabai rawit dan konsentrasi $\mathrm{NaCl}$ secara in vitro

\begin{tabular}{|c|c|c|c|c|c|c|}
\hline \multirow[b]{2}{*}{ Varietas } & \multicolumn{5}{|c|}{ Salinitas (ppm NaCl) } & \multirow[b]{2}{*}{ Rataan } \\
\hline & $\begin{array}{l}\mathrm{G}_{0} \\
(0)\end{array}$ & $\begin{array}{c}\mathrm{G}_{1} \\
(2.500)\end{array}$ & $\begin{array}{c}\mathrm{G}_{2} \\
(5.000)\end{array}$ & $\begin{array}{c}\mathrm{G}_{3} \\
(7.500)\end{array}$ & $\begin{array}{c}\mathrm{G}_{4} \\
(10.000)\end{array}$ & \\
\hline \multicolumn{7}{|c|}{ 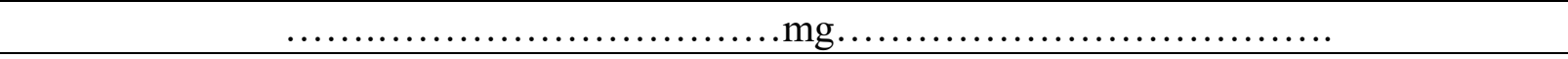 } \\
\hline $\mathrm{V}_{1}$ (Tetra Hijau) & $1.80_{\mathrm{cd}}$ & $0.55 \mathrm{~cd}$ & $0.34_{\mathrm{cd}}$ & $0.21_{\mathrm{cd}}$ & $0.14_{\mathrm{d}}$ & 0.61 \\
\hline $\mathrm{V}_{2}$ (Pedas) & $0.47_{\mathrm{cd}}$ & $0.55_{\mathrm{cd}}$ & $0.68 \mathrm{~cd}$ & $0.57_{\mathrm{cd}}$ & $0.29 \mathrm{~cd}$ & 0.51 \\
\hline $\mathrm{V}_{3}$ (Cakra Hijau) & $0.29 \mathrm{~cd}$ & $0.57 \mathrm{~cd}$ & $0.70_{\mathrm{cd}}$ & $0.37 \mathrm{~cd}$ & $0.27 \mathrm{~cd}$ & 0.44 \\
\hline $\mathrm{V}_{4}$ (Sigantung) & $27.99 \mathrm{a}$ & $17.67 \mathrm{~b}$ & $3.37 \mathrm{c}$ & $0.95 \mathrm{~cd}$ & $1.19 \mathrm{~cd}$ & 10.23 \\
\hline V5 (Wijaya) & $0.35_{\mathrm{cd}}$ & $0.38 \mathrm{~cd}$ & $0.28 \mathrm{~cd}$ & $0.04_{d}$ & $0.16_{d}$ & 0.24 \\
\hline $\mathrm{V}_{6}($ Sapade $)$ & $0.72_{\mathrm{cd}}$ & $0.95_{\mathrm{cd}}$ & $1.26_{\mathrm{cd}}$ & $0.17_{\mathrm{d}}$ & $0.40_{\mathrm{cd}}$ & 0.70 \\
\hline $\mathrm{V}_{7}($ Sret $)$ & $2.02_{\mathrm{cd}}$ & $0.21_{\mathrm{cd}}$ & $0.44_{\mathrm{cd}}$ & $0.19_{\mathrm{cd}}$ & $0.16_{d}$ & 0.60 \\
\hline $\mathrm{V}_{8}$ (Bara) & $2.06_{\mathrm{cd}}$ & $1.90_{\mathrm{cd}}$ & $0.08 \mathrm{~d}$ & $0.27_{\mathrm{cd}}$ & $0.11_{d}$ & 0.88 \\
\hline $\mathrm{V}_{9}($ Genie $)$ & $0.38_{\mathrm{cd}}$ & $0.34_{c d}$ & $0.31_{\mathrm{cd}}$ & $0.62_{\mathrm{cd}}$ & $0.53_{\mathrm{cd}}$ & 0.44 \\
\hline $\mathrm{V}_{10}($ Hanna 08$)$ & $0.31_{\mathrm{cd}}$ & $0.16_{d}$ & $0.26_{\mathrm{cd}}$ & $0.21_{\mathrm{cd}}$ & $0.09_{\mathrm{d}}$ & 0.20 \\
\hline Rataan & 3.64 & 2.33 & 0.77 & 0.36 & 0.33 & 1.49 \\
\hline
\end{tabular}

Keterangan: Angka yang diikuti notasi huruf yang berbeda pada kolom dan baris yang sama adalah berbeda nyata berdasarkan Uji Jarak Berganda Duncan pada taraf $5 \%$.

Tabel 3 menunjukkan peningkatan konsentrasi garam meyebabkan bobot basah akar semakin rendah. Perlakuan $\mathrm{G}_{0} \mathrm{~V}_{4}(27.99$ mg) menghasilkan bobot basah akar lebih berat dibandingkan perlakuan lainnya. Sedangkan perlakuan $\mathrm{G}_{3} \mathrm{~V}_{5}$ menghasilkan bobot basah akar terendah $(0.04 \mathrm{mg})$. Pada $\mathrm{V}_{1}, \mathrm{~V}_{2}, \mathrm{~V}_{3}, \mathrm{~V}_{5}, \mathrm{~V}_{6}, \mathrm{~V}_{7} \mathrm{~V}_{8}, \mathrm{~V}_{9}$ dan $\mathrm{V}_{10}$ perlakuan $\mathrm{NaCl}$ mulai kontrol $\left(\mathrm{G}_{0}\right)$ sampai $10.000 \mathrm{ppm}\left(\mathrm{G}_{4}\right)$ tidak mempengaruhi bobot basah akar. Berbeda dengan $\mathrm{V}_{4}$ peningkatan konsentrasi $\mathrm{NaCl}$ sangat mempengaruhi bobot basah akar terutama pada perlakuan kontrol $\left(\mathrm{G}_{0}\right)$ dan konsentrasi $2.500 \mathrm{ppm} \quad\left(\mathrm{G}_{1}\right)$ ditunjukkan dengan penurunan bobot basah akar yang cukup besar, $\mathrm{V}_{4}$ memiliki bobot basah akar yang lebih tinggi dibandingkan dengan varietas lainnya.

Lingkungan yang tidak sesuai menyebabkan tanaman mengalami stess (cekaman) dalam proses metabolismenya sehingga hasil tanaman menjadi rendah, sebaliknya lingkungan tumbuh yang optimum akan mendukung pertumbuhan tanaman untuk tumbuh maksimal (Dolyna, 2008). Hal ini ditunjukkan pada beberapa parameter memiliki data rataan tertinggi pada perlakuan $\mathrm{NaCl} 0$ ppm $\left(\mathrm{G}_{0}\right)$ untuk bobot basah tajuk dan bobot basah akar. Peningkatan konsentrasi $\mathrm{NaCl}$ secara terus menerus menyebabkan kerusakan jaringan sehingga tanaman 
tumbuh abnormal atau mati (Sujitno dan Dianawati, 2013).

Berdasarkan hasil analisis ragam gabungan diketahui varietas Sigantung memiliki rataan tertinggi pada seluruh parameter amatan, sehingga varietas Sigantung memiliki sifat toleran terhadap cekaman salinitas. Hasil analisis ragam ini dapat menjadi gambaran ketahanan ketiga varietas cabai rawit hingga fase produksi. Hal ini dijelaskan Taufik et al. (2009) penelitian karakterisasi pada fase bibit dalam kondisi tercekam salin dapat menjadi cerminan produksi suatu tanaman. Sehingga varietas tersebut dapat menjadi varietas cabai rawit yang toleran cekaman Salinitas untuk kemudian diuji hingga fase produksi. Hal ini dijelaskan Sitompul dan Guritno (1995) perbedaan pertumbuhan awal pertumbuhan akan menjadi modal yang potensial untuk menghasilkan perbedaan pertumbuhan kemudian, sebagai contoh tanaman yang memiiki daun lebih banyak pada awal pertumbuhan akan lebih cepat tumbuh karena kemampuan menghasilkan fotosintat yang lebih tinggi dibandingkan tanaman dengan luas daun lebih rendah.

\section{SIMPULAN}

Perlakuan varietas, konsentrasi $\mathrm{NaCl}$ dan interaksi keduanya berpengaruh nyata pada bobot basah tajuk dan bobot basah akar. Varietas Sigantung memiliki rataan tertinggi pada seluruh parameter amatan.

\section{DAFTAR PUSTAKA}

Akbar, R. 2010. Penapisan Beberapa Varietas Kedelai (Glycine $\max$ L. Merril.) Terhadap Beberapa Konsentrasi Garam $\mathrm{NaCl}$ Secara Kultur In Vitro. Fakultas Pertanian Universitas Sumatera Utara. Medan.

Djukri. 2009. Cekaman Salinitas Terhadap Pertumbuhan Tanaman. Fakultas MIPA. Universitas Negeri Yogyakarta. Yogyakarta.

Dolyn, M. H. D. 2008. Pengaruh Lingkungan Tumbuh yang Berbeda Terhadap
Kualitas Buah Stroberi (Fragaria $x$ ananassa Duch.). Departemen Agronomi dan Hortikultura. Institut Pertanian Bogor. Bogor.

Fauziah, L. K. 2016. Seleksi In Vitro dan Karakterisasi Planlet Selada (Lactuca sativa L.) Resisten Terhadap Cekaman Kekeringan dengan Poly Ethylene Glycol (PEG) 6000. Fakultas Matematika dan Ilmu Pengetahuan Alam Universitas Lampung. Bandar Lampung.

Kasim, N. 2010. Penggunaan Agen Seleksi $\mathrm{NaCl}$ untuk Uji Ketahanan Salinitas Beberapa Varietas Jagung (Zea mays L.). Jurusan Budidaya Pertanian. Universitas Hasanuddin. Makasar.

Nauly, D. 2016. Fluktuasi Dan Disparitas Harga Cabai Di Indonesia. Universitas Muhammadiyah Jakarta. Jakarta.

Salisbury, FB., \& CW. Ross. 1995. Fisiologi Tumbuhan. Jilid 1. Terjemahan dari Plant Physiology 4th Edition oleh Diah R. Lukman dan Sumaryono, ITB. Bandung. Dalam Ridwan, Tri H. dan Witjaksono. 2016. Uji Toleransi Tanaman Kentang Hitam (Plectranthus rotundifolius (Poir.) Spreng.) Hasil Radiasi Sinar Gamma terhadap Cekaman Kekeringan. Jurnal Biologi Indonesia 12(1): 4148.

Sudana, W. 2005. Potensi dan Prospek Lahan Rawa Sebagai Sumber Produksi Pertanian. Balai Pengkajian dan Pengembangan Teknologi Pertanian. Bogor.

Sujitno, E dan M. Dianawati. 2015. Produksi panen berbagai varietas unggul baru cabai rawit (Capsicum frutescens) di lahan kering Kabupaten Garut, Jawa Barat. Balai Pengkajian Teknologi Pertanian. Bandung.

Sitompul, S. M. dan B. Guritno. 1995. Analisis Pertumbuhan Tanaman. Gadjah Mada Press. Yogyakarta.

Sunarto. 2001. Toleransi Kedelai terhadap Tanah Salin. Fakultas Pertanian 
Universitas Jenderal Soedirman. Purwekerto.

Suwignyo, R. A. 2007. Ketahanan Tanaman Padi Terhadap Kondisi Terendam: Pemahaman Terhadap Karakter Fisiologis unntuk Mendapatkan Kultivar Padi yang Toleran di Lahan Rawa Lebak. Kongres Ilmu Pengetahuan Wilayah Indonesia Bagian Barat. Fakultas Pertanian Universitas Sriwijaya. Palembang.

Taufik, M., Gustian, A. Syarif dan I. Suliansyah. 2009. Seleksi Hibrida F1 Kakao Berproduksi Tinggi pada Fase Bibit Memanfaatkan Analisis Diskriminan. Universitas Bengkulu. Bengkulu.
Widiayani, N. 2016. Daya Kecambah Benih Beberapa Varietas Jagung Pada Berbagai Tingkat Radiasi Sinar Gamma Dan Tingkat Salinitas. Fakultas Pertanian Universitas Hasanuddin. Makassar. 